\title{
Assessment and Practice of Female Health Care Workers Regarding Risk of Breast Cancer and Screening Methods Cross-Sectional Study, Saudi Arabia
}

\author{
Majed Saeed Alshahrani1 ${ }^{(0)}$, Salem Ali Alatef Sultan' ${ }^{\circledR}$, Sultan Yahya Alhammam², \\ Ibrahim Hazzaa Alshaghath2, Emad Hassan Abdullah Alfayez², Mahdi Ali Mahdi Alyami2, \\ Eman Hassan Abdullah Alfayez ${ }^{3}$
}

\author{
${ }^{1}$ Department of Obstetrics and Gynecology, College of Medicine, Najran University, Najran, KSA \\ ${ }^{2}$ College of Medicine, Najran University, Najran, KSA \\ ${ }^{3}$ College of Medicine, AlFarabi Colleges of Medicine, Dentistry and Nursing, Riyadh, KSA \\ Email: alkozeem@hotmail.com,DRSS_01@hotmail.com, sultanhammam932@gmail.com, ibra94nu@gmail.com, \\ emadfayez61@gmail.com,em201119@gmail.com,111order111@gmail.com
}

How to cite this paper: Alshahrani, M.S., Sultan, S.A.A., Alhammam, S.Y., Alshaghath, I.H., Alfayez, E.H.A., Alyami, M.A.M. and Alfayez, E.H.A. (2020) Workers Regarding Risk of Breast Cancer and Screening Methods Cross-Sectional Study, Saudi Arabia. Open Journal of Obstetrics and Gynecology, 10, 201-212.

https://doi.org/10.4236/ojog.2020.1020017

Received: January 7, 2020

Accepted: February 3, 2020

Published: February 6, 2020

Copyright $\odot 2020$ by author(s) and Scientific Research Publishing Inc. This work is licensed under the Creative Commons Attribution-NonCommercial International License (CC BY-NC 4.0). http://creativecommons.org/licenses/by-nc/4.0/ (c) (i) \&) Open Access

\begin{abstract}
Background: A high level of knowledge practice among female health care workers regarding risk factors for breast cancer and screening methods is important in increasing awareness in the general population. Objective: To assess the knowledge and practice of female health care workers in Najran about breast cancer and their behavior in relation to breast screening methods. Methods: This cross-sectional study was conducted using an interviewer administered questionnaire-based survey method at a Maternity and Children's Hospital, primary health care centers and King Khalid Hospital at Najran City, Saudi Arabia. The study was conducted from April 2019 to June 2019. A total of 493 participants were included. Data were collected, coded, and entered into a statistical software program (IBM SPSS version 25) for statistical analysis. Result: Among the 493 participants, 17\% had good knowledge about the risk factors for breast cancer, while $37 \%$ had moderate knowledge and $46 \%$ had poor knowledge. Knowledge and attitudes regarding methods of screening for breast cancer was poor in $57.2 \%$ of the participants, moderate in $36.5 \%$ and only $6.3 \%$ had good awareness. In terms of barriers to screening, $47.3 \%, 50.5 \%$ and $27.2 \%$ were unaware of mammograms, clinical breast examinations and self-examination, respectively. Among the participants, $42.0 \%$ obtained relevant information from symposia, workshops and social media. Conclusion: The level of knowledge and attitudes among female health care workers regarding risk factors of breast screening is low.
\end{abstract}


Urgent intervention by the health care system in Saudi Arabia is required to increase the awareness of breast cancer screening among health care workers.

\section{Keywords}

Breast Cancer, Screening, Health Care Providers, Saudi Arabia, Risk Factors

\section{Introduction}

Breast cancer is the most common cancer in women both in the developed and developing world. Breast cancer is the second most common cancer overall accounting for $11.9 \%$ of all cancers, but ranks $5^{\text {th }}$ globally as a cause of death, accounting for $6.4 \%$ of all deaths [1]. In Saudi Arabia, breast the most common cancer affecting Saudi women, with $25 \%$ of all women diagnosed with breast cancer [2]. Saudi women with breast cancer usually present at an advance stages [3]. Therefore, early detection remains the cornerstone of breast cancer management to improve patient outcomes and survival. Mammography, clinical breast examination, and breast self-examination are the secondary prevention methods used for screening breast cancer. There are many risk factors for breast cancer including age, with the incidence increasing with age, and approximately doubling every 10 years until menopause [4]. In Saudi Arabia, 2741 new cases of cancer were reported in 2012 among them 20\% diagnosed with breast cancer [5].

The a high level of knowledge practice among female health care workers regarding risk factors for breast cancer and screening methods is important in increasing awareness in the general population. Therefore, in this study, we assessed the knowledge of female health care workers in Najran about breast cancer and their behavior in relation to breast screening methods.

\section{Methods}

This cross-sectional study was conducted using an electronic administered questionnaire at Maternity and Children's hospitals, primary health care centers and King Khalid Hospital at Najran City, Saudi Arabia. All female health care workers (Saudi and non-Saudi) were included and agreed to participate in this study. Those who refused to participate were excluded. The study was conducted from April 2019 to June 2019.

A total of 493 participants were included, with margin of error set at $5 \%$ and a confidence interval of $95 \%$. An ethical approval for this study was obtained from the research committee at the College of Medicine, Najran University before the start of the study. Data were obtained by a research team who administered the electronic questionnaire directly to female health care workers. Each participant took five minutes to complete the questionnaire, which consisted of three parts:

Part 1: Sociodemographic data: age, nationality, occupation, marital status, medical history, family history of breast disease, ages at menarche, marriage and 
parity.

Part 2: Items related to awareness risk of breast cancer and knowledge of screening methods.

Part 3: Items related to the practice of screening methods and barriers to their practice.

\section{Statistical analysis}

Data collected, coded, and entered into a statistical software program (IBM SPSS version 25). Any correct answer given a score of one point; otherwise, a score of zero given. The discrete scores for the different knowledge domains summed. Knowledge scores categorized relative to the maximum score as follows: poor, $<50 \%$; moderate, $50 \%-75 \%$; and good, $>75 \%$. Descriptive statistics, including frequencies and percentages, used to describe the frequency of each response for the categorical data. The Chi-squared test/Monte Carlo exact test and Fishers exact test used to evaluate between sample characteristics and knowledge level. All statistical analysis performed using two-tailed tests, with an alpha error of 0.05 . $P$-value less than or equal to 0.05 were considered statistical significance.

\section{Results}

In total, 493 women's health care providers were invited to participate in this study. As shown in Figure 1, 17.4\% of the participants had good knowledge about risk factors for breast cancer, while $36.9 \%$ had moderate knowledge. The remaining $45.6 \%$ had only poor knowledge about risk factors for breast cancer. The knowledge and attitude regarding the methods of screening for breast cancer was poor in $57.2 \%$ of the participants, moderate in $36.5 \%$ and only $6.3 \%$ had good awareness.

The demographic data shown in Table 1 demonstrate that majority of participants were Saudi (86.2\%) and aged under 30 years (68.4\%). In total, $68.2 \%$ of the participants were nurses, and $58.6 \%$ were single. No medical disease reported by $91 \%$ of participants and $86 \%$ had no history of breast disease.

As shown in Table 2, analysis of the distribution of predictors of risk factors for breast cancer revealed that nationality was the most significant predictor $(P=$

\section{Breast Cancer Awareness}



Figure 1. General knowledge level. 
Table 1. Socio-demographic data.

\begin{tabular}{lll}
\hline Demographic data & & \\
\hline & $n$ & $\%$ \\
\hline
\end{tabular}

Age (years) $n=493$

$\begin{array}{lcc}\text { Less than } 30 & 337 & 68.4 \\ \text { From } 31 \text { to } 40 & 138 & 28 \\ \text { From } 41 \text { to } 50 & 18 & 3.7\end{array}$

Nationality $n=493$

$\begin{array}{lcc}\text { Saudi } & 425 & 86.2 \\ \text { Non-Saudi } & 68 & 13.8\end{array}$

Occupation $n=493$

Doctor 51

Pharmacist 24

Nurse

Physiotherapist

Lab specialist

Marital status $n=493$

Single
Married
Divorced
Widowed

Medical history $n=493$

Nil 452

Diabetes mellitus

Hypertension

Other

Surgical history $n=493$

$\begin{array}{lll}\text { Yes } & 81 & 16.4 \\ \text { No } & 412 & 83.6\end{array}$

Medication history $n=493$

$\begin{array}{lll}\text { Yes } & 64 & 13 \\ \text { No } & 429 & 87\end{array}$

Family history of any breast disease $n=493$

$\begin{array}{lcc}\text { Nil } & 426 & 86.4 \\ \text { Aunt } & 30 & 6.1 \\ \text { Grandmother } & 14 & 2.8 \\ \text { Mother } & 8 & 1.6 \\ \text { Sister } & 8 & 1.6 \\ \text { Others } & 7 & 1.4\end{array}$




\section{Continued}

\begin{tabular}{ccc}
\hline Age at menarche (years) $n=493$ & 55 & 11.2 \\
Unknown & 82 & 16.6 \\
Less than 12 & 271 & 55 \\
From 12 to 14 & 85 & 17.2 \\
More than 14 & & \\
Age at marriage (years) $n=493$ & 33 & 6.7 \\
Less than 20 & 152 & 30.8 \\
From 21 to 30 & 18 & 3.7 \\
From 31 to 40 & 1 & 0.2 \\
More than 40 & 289 & 58.6 \\
Not married & & \\
Parity $n=493 \quad 51$ & 10.3 \\
Nulliparous & 153 & 31 \\
Multiparous & 289 & 58.6 \\
Not married & & \\
\hline
\end{tabular}

Table 2. Distribution of the general knowledge level of breast cancer.

\begin{tabular}{|c|c|c|c|c|c|c|c|c|c|c|}
\hline \multirow{3}{*}{\multicolumn{2}{|c|}{ Predictors }} & \multicolumn{8}{|c|}{ General Knowledge Level } & \multirow{3}{*}{$P$} \\
\hline & & \multicolumn{2}{|c|}{ Poor } & \multicolumn{2}{|c|}{ Moderate } & \multicolumn{2}{|c|}{ Good } & \multicolumn{2}{|c|}{ Total } & \\
\hline & & $n$ & $\%$ & $n$ & $\%$ & $n$ & $\%$ & $n$ & $\%$ & \\
\hline \multirow{3}{*}{$\begin{array}{c}\text { Age } \\
\text { (years) }\end{array}$} & Less than 30 & 159 & 47.2 & 127 & 37.7 & 51 & 15.1 & 337 & 100 & \multirow{3}{*}{0.391} \\
\hline & From 31 to 40 & 59 & 42.8 & 48 & 34.8 & 31 & 22.5 & 138 & 100 & \\
\hline & From 41 to 50 & 7 & 38.9 & 7 & 38.9 & 4 & 22.2 & 18 & 100 & \\
\hline \multirow{2}{*}{ Nationality } & Saudi & 212 & 49.9 & 158 & 37.2 & 55 & 12.9 & 425 & 100 & \multirow{2}{*}{$0.000^{*}$} \\
\hline & Non-Saudi & 13 & 19.1 & 24 & 35.3 & 31 & 45.6 & 68 & 100 & \\
\hline \multirow{6}{*}{ Occupation } & Doctor & 16 & 31.4 & 15 & 29.4 & 20 & 39.2 & 51 & 100 & \multirow{6}{*}{$0.007^{\star}$} \\
\hline & Pharmacist & 11 & 45.8 & 9 & 37.5 & 4 & 16.7 & 24 & 100 & \\
\hline & Radiology technologist & 28 & 40.6 & 28 & 40.6 & 13 & 18.8 & 69 & 100 & \\
\hline & Nurse & 165 & 49.1 & 125 & 37.2 & 46 & 13.7 & 336 & 100 & \\
\hline & Physiotherapist & 2 & 28.6 & 4 & 57.1 & 1 & 14.3 & 7 & 100 & \\
\hline & Lab specialist & 3 & 50 & 1 & 16.7 & 2 & 33.3 & 6 & 100 & \\
\hline \multirow{4}{*}{ Marital status } & Single & 126 & 43.6 & 120 & 41.5 & 43 & 14.9 & 289 & 100 & \multirow{4}{*}{$0.039^{*}$} \\
\hline & Married & 88 & 47.1 & 57 & 30.5 & 42 & 22.5 & 187 & 100 & \\
\hline & Divorced & 9 & 64.3 & 5 & 35.7 & 0 & 0 & 14 & 100 & \\
\hline & Widowed & 2 & 66.7 & 0 & 0 & 1 & 33.3 & 3 & 100 & \\
\hline \multirow{4}{*}{ Medical history } & Nil & 205 & 45.4 & 170 & 37.6 & 77 & 17 & 452 & 100 & \multirow{4}{*}{0.650} \\
\hline & Diabetes mellitus & 4 & 36.4 & 4 & 36.4 & 3 & 27.3 & 11 & 100 & \\
\hline & Hypertension & 9 & 50 & 4 & 22.2 & 5 & 27.8 & 18 & 100 & \\
\hline & Other & 7 & 58.3 & 4 & 33.3 & 1 & 8.3 & 12 & 100 & \\
\hline
\end{tabular}




\section{Continued}

\begin{tabular}{|c|c|c|c|c|c|c|c|c|c|c|}
\hline \multirow{2}{*}{ Surgical history } & Yes & 35 & 43.2 & 26 & 32.1 & 20 & 24.7 & 81 & 100 & \multirow{2}{*}{0.161} \\
\hline & No & 190 & 46.1 & 156 & 37.9 & 66 & 16 & 412 & 100 & \\
\hline \multirow{3}{*}{ Medication history } & Yes & 30 & 46.9 & 25 & 39.1 & 9 & 14.1 & 64 & 100 & \multirow{2}{*}{0.741} \\
\hline & No & 195 & 45.5 & 157 & 36.6 & 77 & 17.9 & 429 & 100 & \\
\hline & Nil & 204 & 47.9 & 153 & 35.9 & 69 & 16.2 & 426 & 100 & \multirow{6}{*}{0.079} \\
\hline \multirow{5}{*}{ Family history } & Mother & 2 & 25 & 3 & 37.5 & 3 & 37.5 & 8 & 100 & \\
\hline & Sister & 3 & 37.5 & 4 & 50 & 1 & 12.5 & 8 & 100 & \\
\hline & Grandmother & 4 & 28.6 & 9 & 64.3 & 1 & 7.1 & 14 & 100 & \\
\hline & Aunt & 11 & 36.7 & 9 & 30 & 10 & 33.3 & 30 & 100 & \\
\hline & Others & 1 & 14.3 & 4 & 57.1 & 2 & 28.6 & 7 & 100 & \\
\hline \multirow{5}{*}{$\begin{array}{l}\text { Age at marriage } \\
\text { (years) }\end{array}$} & Less than 20 year & 20 & 60.6 & 10 & 30.3 & 3 & 9.1 & 33 & 100 & \multirow{5}{*}{$0.027^{\star}$} \\
\hline & From 21 to 30 & 73 & 48 & 45 & 29.6 & 34 & 22.4 & 152 & 100 & \\
\hline & From 31 to 40 & 6 & 33.3 & 7 & 38.9 & 5 & 27.8 & 18 & 100 & \\
\hline & More than 40 & 0 & 0 & 0 & 0 & 1 & 100 & 1 & 100 & \\
\hline & Single & 126 & 43.6 & 120 & 41.5 & 43 & 14.9 & 289 & 100 & \\
\hline \multirow{3}{*}{ Parity } & Nulliparous & 27 & 52.9 & 17 & 33.3 & 7 & 13.7 & 51 & 100 & \multirow{3}{*}{$0.043^{\rtimes}$} \\
\hline & Multiparous & 72 & 47.1 & 45 & 29.4 & 36 & 23.5 & 153 & 100 & \\
\hline & Single & 126 & 43.6 & 120 & 41.5 & 43 & 14.9 & 289 & 100 & \\
\hline \multirow{4}{*}{$\begin{array}{l}\text { Age at menarche } \\
\text { (years) }\end{array}$} & Less than 12 & 45 & 54.9 & 25 & 30.5 & 12 & 14.6 & 82 & 100 & \multirow{4}{*}{0.053} \\
\hline & From 12 to 14 & 107 & 39.5 & 109 & 40.2 & 55 & 20.3 & 271 & 100 & \\
\hline & More than 14 & 40 & 47.1 & 31 & 36.5 & 14 & 16.5 & 85 & 100 & \\
\hline & Unknown & 33 & 60 & 17 & 30.9 & 5 & 9.1 & 55 & 100 & \\
\hline
\end{tabular}

$0.001)$, followed by occupation $(P=0.007)$. Age at marriage, marital status and parity were also significant predictors of risk factors for breast cancer $(P=0.027$; $P=0.039$ and $P=0.043$, respectively).

As shown in Table 3, analysis of the distribution of predictors of breast cancer screening methods of breast cancer revealed that nationality was the most significant $(P=0.001)$, followed by occupation and age $(P=0.010 ; P=0.035$, respectively). Other predictors shown not significant for screening of breast cancer.

Table 4 shows the barriers to screening for breast cancer. Overall, 9.9\% of participants had undergone mammograms, $30.4 \%$ had received clinical examination and $59.2 \%$ carried our self-examination. However, among the participants, $47.3 \%, 50.5 \%$ were unaware of mammograms and $27.2 \%$ were not aware of clinical breast examination and self-examination. Furthermore, for each method, $13.4 \%, 4.1 \%$ and $2.4 \%$, respectively, believed that the screening would be painful.

Regarding sources of information, $42.2 \%$ of participants obtained information from attending symposia and workshops and $42 \%$ obtained information from 
Table 3. Distribution of the practice knowledge level of breast cancer screening methods.

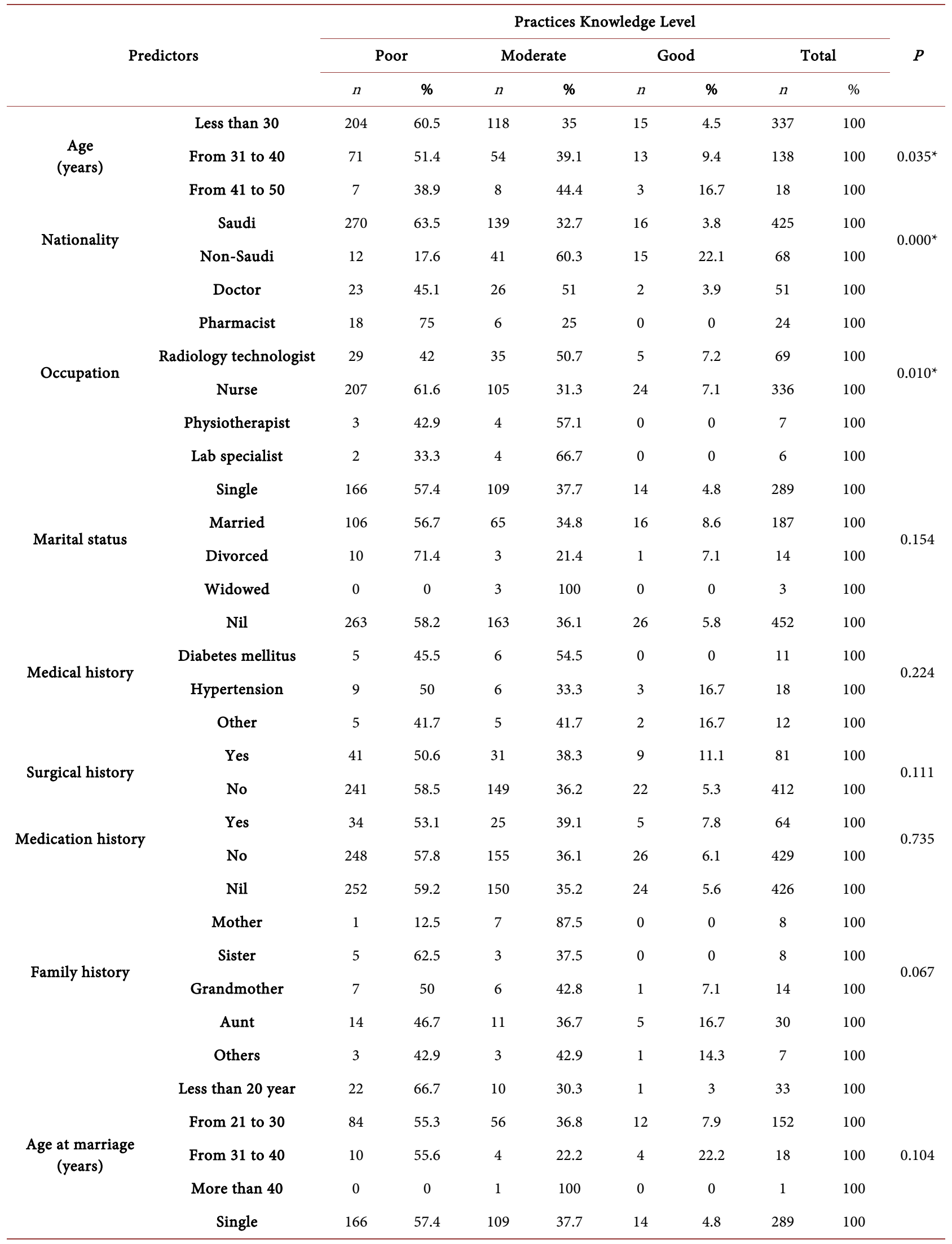




\section{Continued}

\begin{tabular}{ccccccccccc}
\hline & Nulliparous & 31 & 60.8 & 16 & 31.4 & 4 & 7.8 & 51 & 100 \\
Parity & Multiparous & 85 & 55.6 & 55 & 35.9 & 13 & 8.5 & 153 & 100 & 0.553 \\
& Single & 166 & 57.4 & 109 & 37.7 & 14 & 4.8 & 289 & 100 & \\
& Less than 12 & 54 & 65.9 & 24 & 29.3 & 4 & 4.9 & 82 & 100 & \\
& From 12 to 14 & 138 & 50.9 & 113 & 41.7 & 20 & 7.4 & 271 & 100 & 0.053 \\
$\begin{array}{c}\text { Age at menarche } \\
\text { (years) }\end{array}$ & More than 14 & 50 & 58.8 & 30 & 35.3 & 5 & 5.9 & 85 & 100 & \\
& Unknown & 40 & 72.7 & 13 & 23.6 & 2 & 3.6 & 55 & 100 \\
\hline
\end{tabular}

Table 4. Barriers to breast screening methods.

\begin{tabular}{|c|c|c|}
\hline \multicolumn{3}{|c|}{$n=493$} \\
\hline Barriers & $n$ & $\%$ \\
\hline \multicolumn{3}{|c|}{ What's the barrier to you accepting mammogram screening? } \\
\hline Unaware of the screening method & 233 & 47.3 \\
\hline It is harmful & 43 & 8.7 \\
\hline It is expensive & 47 & 9.5 \\
\hline It is painful & 66 & 13.4 \\
\hline Fear of the result & 55 & 11.2 \\
\hline I have had a mammogram & 49 & 9.9 \\
\hline \multicolumn{3}{|l|}{ What's the barrier to do clinical breast examination? } \\
\hline Unaware of the screening method & 250 & 50.7 \\
\hline No female physician & 49 & 9.9 \\
\hline It is painful & 20 & 4.1 \\
\hline Fear of the result & 24 & 4.9 \\
\hline I have had clinical breast examination & 150 & 30.4 \\
\hline \multicolumn{3}{|l|}{ What's the barrier to do breast self-examination? } \\
\hline Unaware of the screening method & 134 & 27.2 \\
\hline No training & 40 & 8.1 \\
\hline It is painful & 12 & 2.4 \\
\hline Fear of the results & 15 & 3 \\
\hline I do self-examination & 292 & 59.2 \\
\hline
\end{tabular}

social media. 9.3\% they don't had information about it and 6.5\% of participants obtained from Campion in mall (Figure 2).

\section{Discussion}

The aim of this study was to evaluate the level of knowledge and practice among female health care workers in Najran. This information is important for ensuring that health care workers have the knowledge required to educate women and improve awareness about breast cancer. Our findings may be useful for planning 


\section{What is your source of information about breast cancer?}

$9.3,9 \%$

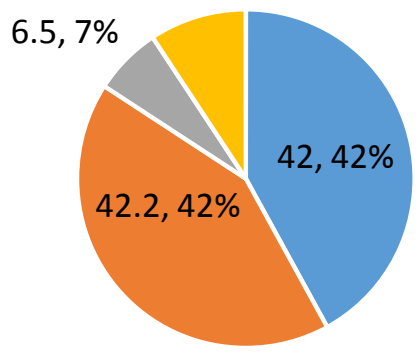

$$
\begin{aligned}
& \text {-Attendance to symposium or workshop } \approx \text { Social media } \\
& \square \text { Campion was established in Mall } \quad \text { I do not have informations }
\end{aligned}
$$

Figure 2. Source of information.

education programs for health care workers about breast cancer and the importance of screening methods. In this study, we found that only $17.4 \%$ of the participants had good knowledge about risk factors for breast cancer and $45.6 \%$ had poor knowledge. A similar study in Benin showed that $12.46 \%$ of the participants had accurate knowledge [6]. Our results are consistent with other reports of poor knowledge about the risk factors of breast cancer among professions [7] [8] In contrast; another study in Nigeria revealed that $67 \%$ of participants had adequate knowledge about the risk factors for breast cancer [9]. The most significant predictor of knowledge of risk factors was nationality, with $45.6 \%$ of non-Saudi participants showing good knowledge, followed by occupation, with $39.2 \%$ of female doctors showing good knowledge compared to all other health care providers. In a similar study conducted in Pakistan, 35\% of nurses had good knowledge about risk factors for breast cancer compared with $13.7 \%$ of nurses in our study [10]. This discrepancy may be due to the difference in training and variations in the participants between the two studies, because $68.2 \%$ of our study participants were nurses. These results highlight the need for improved efforts to raise awareness among health care workers about risk factors for breast cancer.

In this study, $9.9 \%$ of participants had undergone mammogram screening, while $52.3 \%$ were aware of the procedure. The main barrier to attending mammogram screening was the perception that the procedure is painful and fear of the result. Mammograms offered free-of-charge in Saudi Arabia to encourage women to attend screening. In contrast, study in Nigeria it cost effective for them [9]. In another study, approximately $40 \%$ of participants had undergone mammogram screening [11]. Another study in Morocco showed good knowledge about mammograms among doctors, although only $22 \%$ of participants reported having undergone the procedure [12]. In contrast, higher rates of mammogram screening reported in developed countries [13]. The benefit of mammogram is reduced mortality rates and increased survival rate because of 
early detection [14]. Despite all the facilities and the newly designated Breast Cancer Awareness Day in Saudi Arabia, only a small percentage of women undergo mammogram screening. This is due to lack of awareness about the screening and fear of the result. Thus, urgent intervention by the health care system in Saudi Arabia is required to increase the awareness of breast cancer screening through the provision of education programs and workshops for health care workers and to increase the awareness and practice in the general population.

The American Cancer Society recommends clinical breast examination at least every 3 years in women aged from 20 to 39 years and annually, from the age of 40 years onwards [15]. In our study, 30.4\% of participants had received clinical breast examination. It can be speculated that this low percentage is because $9.9 \%$ of these participants requested a female physician. In a study conducted in Bayelsa, only $23.8 \%$ of participants had received clinical breast examination when referred to a female physician [16]. This issue is dependent on religious and cultural constraints that preclude examination by a male doctor. In another study, the participants preferred self-examination to clinical breast examination because of the possibility that the examination conducted by a male doctor [9].

Despite $42 \%$ of the participants in this study obtaining information by attending symposia and workshops, a high percentage of participants still had low levels of knowledge and underwent breast screening. This indicates that the educational material and mammogram programs provided by the health system not used effectively by health care workers. Moreover, $42 \%$ of the participants obtained information via social media, which is unregulated and makes it difficult in determine the scientific validity of the information received.

Some limitations of this study noted. First, our study was limited to Najran City of Saudi Arabia; therefore, our results can't be generalized to the rest of the country and beyond. Second, the majority of participants were nurses; therefore, our study sample is not a representative reflection of the distribution of health care professionals.

\section{Conclusion}

Our study revealed a low level of knowledge and poor attitudes among female health care workers regarding risk factors for breast cancer and screening methods. In addition, it showed superior knowledge among doctors compared with that of nurses. Urgent intervention by the health care system in Saudi Arabia is required to increase the awareness of breast cancer screening among female health care workers and facilitate the transfer of relevant information to the general population.

\section{Compliance with Ethical Standards}

\section{Ethical Approval}

An ethical approval letter has been acquired from the Research Ethics Commit- 
tee, Najran University, Saudi Arabia prior to this study. All the participants in this study will kept anonymity.

\section{Funding}

Self-funding by all researchers.

\section{Informed Consent}

Informed consent obtained from all individual participants included in the study.

\section{Conflicts of Interest}

The authors report no financial affiliations or other conflicts of interest related to the subject of this study.

\section{References}

[1] Ferlay, J., Soerjomataram, I., Dikshit, R., et al. (2015) Cancer Incidence and Mortality Worldwide: Sources, Methods and Major Patterns in GLOBOCAN 2012. International Journal of Cancer, 136, E359-E386. https://doi.org/10.1002/ijc.29210

[2] Saudi Cancer Registry (2008) Cancer Incidence Reports. Saudi Cancer Registry, Saudi Arabia, 36.

http://www.chs.gov.sa/Ar/HealthRecords/CancerRegistry/CancerRegistryReports/I ncidence\%20Report\%202008.pdf

[3] Abolfotouh, M.A., Banimustafa, A.A., Mahfouz, A.A. and Al-assiri, M.H. (2015) Using the Health Belief Model to Predict Breast Self Examination among Saudi Women. BMC Public Health, 15, Article No. 1163.

https://doi.org/10.1186/s12889-015-2510-y

[4] McPherson, K., Steel, C.M. and Dixon, J.M. (2000) ABC of Breast Diseases. Breast Cancer-Epidemiology, Risk Factors, and Genetics. BMJ, 321, 624-628. https://doi.org/10.1136/bmj.321.7261.624

[5] Ministry of Health in Saudi Arabia (2012) National Campaign for Breast Cancer Awareness.

http://www.moh.gov.sa/en/HealthAwareness/Campaigns/Breastcancer/Pages/defaul t.aspx

[6] Achille, O.A.A., Salifou, K., Hounkponou, A.F., et al. (2017) Knowledge, Attitudes and Practices of Health Care Professionals as Regards Breast Cancer in the Municipality of Parakou (Benin) in 2015. Reproductive System and Sexual Disorders, 6, 216. https://doi.org/10.4172/2161-038X.1000216

[7] Akhigbe, A.O. and Omuemu, V.O. (2009) Knowledge, Attitudes and Practice of Breast Cancer Screening among Female Health Workers in a Nigerian Urban City. BMC Cancer, 9, Article No. 203. https://doi.org/10.1186/1471-2407-9-203

[8] Kiguli-Malwadde, E., Mubuuke, A.G., Businge, F., et al. (2010) Current Knowledge, Attitudes and Practices of Women on Breast Cancer and Mammography at Mulago Hospital. Pan African Medical Journal, 5, 9.

[9] Oche, M.O., Ayodele, S.O. and Umar, A.S. (2012) Breast Cancer and Mammography: Current Knowledge, Attitudes and Practices of Female Health Workers in a Tertiary Health Institution in Northern Nigeria. Public Health Research, 2, 114-119. https://doi.org/10.5923/j.phr.20120205.01

[10] Kumar, S., Imam, A.M., Manzoor, N.F. and Masood, N. (2009) Knowledge, Attitude 
and Preventive Practices for Breast Cancer among Health Care Professionals at Aga Khan Hospital Karachi. Journal of Pakistan Medical Association, 59, 474-478.

[11] Zeru, Y., Sena, L. and Shaweno, T. (2019) Knowledge, Attitude, Practice, and Associated Factors of Breast Cancer Self-Examination among Urban Health Extension Workers in Addis Ababa, Central Ethiopia. Journal of Midwifery and Reproductive Health, 7, 1662-1672.

[12] Ghanem, S., Glaoui, M., Elkhoyaali, S., et al. (2011) Knowledge of Risk Factors, Beliefs and Practices of Female Healthcare Professionals towards Breast Cancer, Morocco. Pan African Medical Journal, 10, 21.

https://doi.org/10.4314/pamj.v10i0.72231

[13] Rosenman, K.D., Gardiner, J., Swanson, G.M., Mullan, P. and Zhu, Z. (1995) US Farm Women's Participation in Breast Cancer Screening Practices. Cancer, 75, 47-53.

https://doi.org/10.1002/1097-0142(19950101)75:1<47::AID-CNCR2820750110>3.0. $\underline{\mathrm{CO} ; 2-\mathrm{D}}$

[14] Nelson, H.D., Tyne, K., Naik, A., et al. (2009) Screening for Breast Cancer: An Update for the US Preventive Services Task Force. Annals of Internal Medicine, 151, 727. https://doi.org/10.7326/0003-4819-151-10-200911170-00009

[15] Smith, R.A., Cokkinides, V. and Eyre, H.J. (2005) American Cancer Society Guidelines for the Early Detection of Cancer, 2005. CA: A Cancer Journal for Clinicians, 55, 31-44. https://doi.org/10.3322/canjclin.55.1.31

[16] Allagoa, D.O., Uwaezuoke, S.C. and Kotingo, E.L. (2017) Knowledge, Practice and Attitude of Breast Self, Clinical Breast and Mammographic Examinations amongst Medical Doctors in Bayelsa State. Port Harcourt Medical Journal, 11, 26-33. https://doi.org/10.4103/phmj.phmj_11_17 